\title{
CARACTERISTICAS DE UMA FAVELA DA REGIÃO DA GRANDE SÃO PAULO
}

\author{
Maria Jacyra de Campos Nogueira* \\ Estudantes**
}

NOGUEIRA, M. J. C. et al - Características de uma favela da região da Grande São Paulo. Rev. Esc. Enf. USP, 10(2): 230-248, 1976.

Os autores descrevem os resultados de um levantamento de condições sócio-sanitárias feito em uma favela da Região da Grande São Paulo, área industrializada do sudeste brasileiro.

\section{INTRODUÇÃO}

O presente trabalho relata uma experiência realizada junto a uma favela do município de Osasco, cidade pertencente à região da Grande São Paulo.

O levantamento das características da referida favela teve, como primeiro objetivo, fornecer informações a uma comissão especial nomeada pela prefeitura do município de Osasco, comissão esta encarregada de elaborar um plano de desfavelamento.

O segundo objetivo do trabalho foi o de proporcionar experiência a grupos de alunos que cursavam o último ano do curso de graduação em Enfermagem da Escola de Enfermagem da Universidade de São Paulo e que se habilitavam em Enfermagem em Saúde Pública.

* Professor Assistente Doutor do Departamento de Enfermagem Médico-Cirúrgico da Escola de Enfermagem da USP.

** Alunos do curso de graduação da Escola de Enfermagem da USP: Amélia Tatsukawa, Ana Maria Miura, Carmem A. da Silva, Circeia A. de Andrade, Denise Toledo, Doralice de Souza, Emilia E. Kawamoto, Eunice N. Numata, Janet Russev, Jeanete M. S. Bueno, Miako Miura, Paula Menini, Reiko Koshiyama e Telma Machado. 


\section{MATERIAL E MÉTODO}

O levantamento das características sócio-sanitárias da favela constou do seguinte:

- identificação da área ocupada pelos moradores, por meio de mapas fornecidos pela prefeitura local;

- identificação das vias de acesso à favela, por meio de entrevistas com alguns moradores do bairro;

- preparo dos moradores da favela para colaborar no levantamento;

- numeração dos barracos e confecção de um mapa da área geográfica da favela;

- entrevistas, por meio de formulários, com os moradores da favela e com o presidente da associação de amigos do bairro local.

Para coletar as informações a respeito da vida das famílias residentes na favela, foram entrevistadas as seguintes pessoas encontradas em casa no momento do levantamento: 27 mulheres (donas de casa), 17 homens (chefes de família), 4 mulheres (chefes de família), 5 filhos maiores de dezoito anos e 2 irmãos dos chefes de família, maiores de 18 anos.

\section{RESULTADOS}

\section{Habitação}

A favela possuia 58 barracos e foram entrevistados moradores de 55 deles $(94,8 \%)$. Localizava-se num bairro do município de Osasco que fazia divisa com o município de São Paulo e estava implantada num terreno baldio em declive, pertencente à prefeitura local. Ocupava uma área de aproximadamente $15.800 \mathrm{~m}^{2}$, atravessada por um córrego para onde convergiam, por meio de valas, as águas residuárias oriundas de todos os barracos ali existentes.

Das 55 famílias, $33(60 \%)$ utilizavam fossa negra e as $25(40 \%)$ restantes jogavam os dejetos no solo em torno do barraco. 
Algumas famílias (39\%) compartilhavam o uso da fossa com os vizinhos e os barracos não ofereciam condições mínimas para abrigo, segurança e conforto dos seus moradores, apresentando-se ainda em péssimas condições de limpeza.

Com relação ao tipo de material empregado na construção dos barracos, verificou-se que, em 52 deles $(94,5 \%)$, era madeira obtida de alguns restos de caixotes. Somente $24(45 \%)$ possuiam alguma forma de piso, pois, nos restantes, o chão era de terra batida. Dez barracos $(5,5 \%)$ eram feitos de madeira e papelão obtidos de restos de caixas e caixotes.

Quase a totalidade dos barracos $(96,4 \%)$ pertencia aos seus moradores, tendo sido construídos por eles próprios. Somente 2 famílias $(3,6 \%)$ moravam em barracos emprestados por parentes. Constatou-se, ainda, que todas as famílias possuiam uma área livre em torno da habitação mas, em apenas uma delas, o chão era cimentado. Essa área em torno dos barracos, por outro lado, era de uso coletivo, isto é, para mais de uma família, ou seja para 34 famílias $(61,4 \%)$.

Encontrou-se um total de 342 pessoas residindo em 56 barracos, dando uma média de 6,2 pessoas por habitação, sendo que 37 $(67,8 \%)$ famílias residiam em barracos de um único cômodo.

A relação cama por pessoa existente era de 0,7 . Foi estabelecido, como critério, que as camas de casal equivaliam a duas de solteiro e cada berço a uma cama.

Com relação ao abastecimento de água, verificou-se que $53(96,4 \%)$ famílias se utilizavam de água de poço, todos eles inadequadamente construídos e conservados. Apenas uma família informou que se utilizava da rede de abastecimento público, indo buscar água na casa de alguns vizinhos que moravam fora da favela, e uma família informou que se abastecia de água de uma mina que existia por perto. Quanto ao tratamento de água domiciliar, somente $8(13,7 \%)$ famílias informaram que o realizavam, sendo a filtração o método utilizado.

O lixo da favela tinha o seguinte destino: $41(74,5 \%)$ famílias jogavam-no em terrenos baldios localizados na vizinhança ou no 
próprio terreno ao lado dos barracos, ou ainda, no córrego que atravessava a favela. Apenas $14(25,5 \%)$ indicaram que o lixo era incinerado ou coletado pela prefeitura local.

Grande parte das famílias $(96,3 \%)$ indicou possuir animais domésticos (cães e gatos) e todas informaram existirem muitos ratos e moscas, principalmente nos locais onde era jogado o lixo.

\section{População}

A distribuição dos 342 moradores da favela, de acordo com a idade, sexo, estado civil, religião, escolaridade, encontram-se nas tabelas $1,2,3$ e 4. Ainda foi feita a distribuição de acordo com o fato de os moradores não serem registrados (tabela 5).

TABELA 1

SEXO E IDADE

\begin{tabular}{c|r|r|r|r|r|r}
\hline Idade Sexo & \multicolumn{2}{|c|}{ Masculino } & \multicolumn{2}{c|}{ Feminino } & \multicolumn{2}{c}{ Total } \\
N.o & \multicolumn{1}{|c|}{$\%$} & \multicolumn{1}{c}{ N. } & \multicolumn{1}{c}{$\%$} & N. & \multicolumn{1}{c}{$\%$} \\
\hline $0-1$ & 8 & 4,8 & 4 & 2,3 & 12 & 3,5 \\
$1-4$ & 15 & 8,9 & 12 & 6,9 & 27 & 7,9 \\
$4-7$ & 18 & 10,7 & 21 & 12,1 & 39 & 11,4 \\
$7-12$ & 41 & 24,4 & 30 & 17,2 & 71 & 20,8 \\
$12-20$ & 34 & 20,1 & 45 & 25,8 & 79 & 23,1 \\
$20-30$ & 15 & 8,9 & 16 & 9,2 & 31 & 9,1 \\
$30-40$ & 17 & 10,1 & 17 & 9,8 & 34 & 9,9 \\
$40-50$ & 12 & 7,1 & 19 & 10,9 & 31 & 9,1 \\
$50+$ & 8 & 4,8 & 10 & 5,7 & 18 & 5,2 \\
\hline Total & 168 & 100,0 & 174 & 100,0 & 342 & 100,0 \\
\hline
\end{tabular}

TABELA 2

ESTADO CIVIL DOS ADULTOS*

\begin{tabular}{l|r|r}
\hline Estado civil & N. & $\%$ \\
\hline Casado & 77 & 46,7 \\
Solteiro & 66 & 40,0 \\
Viúvo & 12 & 7,3 \\
Separado & 8 & 4,8 \\
União livre** & 2 & 1,2 \\
\hline \multicolumn{1}{c|}{ Total } & 165 & 100,0 \\
\hline
\end{tabular}

* indivíduos maiores de 14 anos.

** vivendo maritalmente. 
TABELA 3

\begin{tabular}{l|r|r}
\hline RELIGI̊̊O & $\mathrm{N}^{\circ}$ & $\%$ \\
\hline Católica & 283 & 83,0 \\
Protestante & 51 & 15,0 \\
Espírita & 2 & 0,6 \\
Sem religião & 3 & 1,0 \\
Não sabe & 3 & 1,0 \\
\hline \multicolumn{1}{c|}{ Total } & 342 & 100,0 \\
\hline
\end{tabular}

TABELA 4

ESCOLARIDADE*

\begin{tabular}{|c|c|c|c|c|c|c|}
\hline \multirow{2}{*}{ Grau $\begin{array}{c}\text { Sexo } \\
\text { Escolaridade }\end{array}$} & \multicolumn{2}{|c|}{ Masculino } & \multicolumn{2}{|c|}{ Feminino } & \multicolumn{2}{|c|}{ Total } \\
\hline & N. ${ }^{\circ}$ & $\%$ & N. ${ }^{\circ}$ & $\%$ & N. & $\%$ \\
\hline Primário incompleto & 61 & 48,0 & 48 & 35,0 & 109 & 41,3 \\
\hline Analfabeto & 16 & 12,6 & 39 & 28,5 & 55 & 20,8 \\
\hline Primário completo & 14 & 11,0 & 25 & 18,3 & 39 & 14,8 \\
\hline Sabe ler e escrever & 18 & 14,2 & 16 & 11,7 & 34 & 12,8 \\
\hline Secundário incompleto & 13 & 10,2 & 9 & 6,5 & 22 & 8,3 \\
\hline Secundário completo & 1 & 0,4 & - & - & 1 & 0,4 \\
\hline Outros & 4 & 3,5 & 二 & - & 4 & 3,5 \\
\hline Total & 127 & 100,0 & 137 & 100,0 & 264 & 100,0 \\
\hline
\end{tabular}

* maiores de 7 anos de idade.

TABELA 5

MORADORES DA FAVELA QUE POSSUIAM E NÃO POSSUIAM CERTIDÃO DE NASCIMENTO

\begin{tabular}{l|c|c|r|r|r|r}
\hline \multirow{2}{*}{ Certidão } & \multicolumn{2}{|c|}{ Sim } & \multicolumn{2}{c|}{ Não } & \multicolumn{2}{c}{ Total } \\
\cline { 2 - 7 } & N. $^{\circ}$ & $\%$ & N. $^{\circ}$ & $\%$ & N. $^{\circ}$ & $\%$ \\
\hline Menores de 14 anos & 161 & 47,8 & 16 & 4,7 & 177 & 52,0 \\
Maiores de 14 anos & 128 & 37,4 & 37 & 9,7 & 165 & 48,0 \\
\hline Total & 289 & 85,2 & 53 & 14,4 & 342 & 100,0 \\
\hline
\end{tabular}

3. Condições econômicas

Houve dificuldade para a coleta de dados sobre a renda familiar ou salário que recebiam os favelados que trabalhavam.

Segundo informações do presidente da associação de amigos do bairro local, "as condições econômicas dos moradores era precária, os salários muito baixos e existia um grande número de homens e crian- 
ças que não trabalhavam, alguns vivendo dos salários das mulheres que eram empregadas domésticas".

De acordo com o levantamento, apenas 55 adultos (16\%) trabalhavam (Tabela 6), e dentre as suas ocupações, a mais freqüente era a de operário de fábrica, seguida da de empregada doméstica.

Das 58 famílias, $39(86,6 \%)$ possuiam rádio, $5(11,1 \%)$ possuiam televisão e 1 possuia vitrola.

TABELA 6

OCUPAÇÃO E PREVIDENCIA SOCIAL DOS QUE TRABALHAVAM*

\begin{tabular}{|c|c|c|c|c|}
\hline Pre & Informa & Informa & Não sabe & Total \\
\hline Ocupação & $\begin{array}{c}\text { ter } \\
\text { direito }\end{array}$ & $\begin{array}{l}\text { não ter } \\
\text { direito }\end{array}$ & informar & N. $\%$ \\
\hline Operário de fábrica & 13 & 3 & 4 & 2036,3 \\
\hline Empregada doméstica & 3 & 10 & - & $13 \quad 23,6$ \\
\hline Servente de pedreiro & 4 & 2 & - & 611,0 \\
\hline Ajudante de caminhão & - & 7 & - & 5,5 \\
\hline Carregador & - & 2 & - & 3,6 \\
\hline Não sabe informar & 2 & - & - & 3,6 \\
\hline Outros** & 二 & - & 7 & $\begin{array}{ll}7 & 14,5\end{array}$ \\
\hline Total & 22 & 22 & 11 & 55 \\
\hline
\end{tabular}

* maiores de 14 anos.

** servente de hospital, pintor, carpinteiro, faxineiro, lanterninha de cinema, guarda-noturno e aposentado.

Das 55 famílias, apenas 17 eram servidas pela rede de energia elétrica; 1 família possuia geladeira, 2 possuiam ferro elétrico. Nos barracos em que não havia eletricidade, as famílias utilizavam lampião, lamparinas e velas para iluminação.

Todas as famílias possuiam fogão a gás localizados dentro dos barracos com exceção de uma família que possuia 2 fogões um dos quais a gás e outro a lenha, este último situado fora do barraco.

\section{Alimentação}

Os locais onde as famílias adquiriam seus alimentos, bem como o tipo de alimentação utilizada, se encontram nas tabelas 7 e 8 . 
TABELA 7

LOC̣AIS ONDE ADQUIRIAM ALIMENTOS*

\begin{tabular}{l|l|c}
\hline \multicolumn{1}{c|}{ Locais } & N. ${ }^{\circ}$ & $\%$ \\
\hline Armazém & 28 & 34,1 \\
Supermercado & 25 & 30,5 \\
Feira livre & 18 & 21,9 \\
Outros** & 11 & 13,4 \\
\hline \multicolumn{1}{c|}{ Total } & 82 & 100,0 \\
\hline
\end{tabular}

* algumas famílias adquiriam alimentos em mais de um local.

** outros locais: igreja, vendedores ambulantes, CEASA e bares.

TABELA 8

ALIMENTOS MAIS CONSUMIDOS PELAS FAMILIAS, EM UM DIA*

\begin{tabular}{l|c|c}
\hline \multirow{2}{*}{ Tipo de alimentos } & \multicolumn{2}{|c}{ Famílias que consumiam } \\
\cline { 2 - 3 } & $\mathrm{N} .^{\circ}$ & $\%$ \\
\hline Arroz & 52 & 20,8 \\
Feijão & 48 & 19,3 \\
Café & 37 & 14,8 \\
Pão & 33 & 13,3 \\
Carne & 16 & 6,4 \\
Verduras & 13 & 5,0 \\
Ovos & 12 & 4,8 \\
Legumes & 8 & 3,2 \\
Leite & 6 & 2,4 \\
Frutas & 3 & 1,2 \\
Outros ** & 21 & 8,4 \\
\hline \multicolumn{1}{c}{ Total } & 249 & 100,0 \\
\hline
\end{tabular}

* as famílias consumiam diariamente mais de um tipo de alimento.

** farinha de mandioca, peixe, chá, macarrão, manteiga e milho.

Quanto ao aproveitamento do terreno existente em torno dos barracos para o plantio de frutas ou verduras, das 58 famílias, apenas $14(8,1 \%)$ possuiam uma pequena horta doméstica, e $13(7,5 \%)$ possuiam alguma árvore frutífera (principalmente bananeiras).

5. Saúde e tratamento das doenças

Não foi possível verificar com precisão as condições de vacinação da população porque as pessoas entrevistadas não sabiam informar a respeito.

Das 342 pessoas existentes, somente $142(41 \%)$ informaram ter tomado alguma vacina. As vacinas que a população lembrava 
ter recebido foram, em primeiro lugar, a antivariólica e em segundo, a Sabin e a antitetânica. Entre as pessoas vacinadas, 65 (45\%) eram adultas e $77(54,2 \%)$ eram crianças.

Dos 55 adultos que trabalhavam, $30(54,5 \%)$ informaram ter direito a INPS, $20(36,3 \%)$ informaram não ter direito e $5(9,0 \%)$ não sabiam informar se tinham ou não direito a INPS.

Quanto aos recursos de saúde de que as famílias mais se utilizavam em casos de doença, apresentam-se os seguintes, em ordem decrescente:

$10^{\circ}$ hospital (pronto-socorro da prefeitura local);

$2 .^{\circ}$ posto de saúde (da prefeitura local);

3. farmacêutico;

$4 .^{\circ}$ INPS;

$5 .^{\circ}$ médico particular;

$60^{\circ}$ benzedor.

Nas 55 famílias entrevistadas, $7(12,7 \%)$ adultos e crianças de 27 famílias $(49,9 \%)$ tinham recebido assistência dentária ultimamente.

Das 53 mães, $16(30 \%)$ costumavam dar à luz no hospital, $14(26,4 \%)$ em casa assistidas por parentes ou curiosas; $23(43,3 \%)$ tiveram alguns filhos em casa e outros no hospital, dependendo das facilidades do local onde haviam morado. Foi verificado que havia uma "curiosa" morando na favela.

As causas de morte entre as pessoas das famílias dos favelados, segundo suas informações foram as seguintes, em ordem decrescente:

1. causas desconhecidas;

2. abortos;

3. nati-mortos de causas desconhecidas;

$4 .^{\circ}$ desidratação;

$50^{\circ}$ meningite.

Dentre as doenças existentes nas famílias, por ocasião do levantamento, sobressairam-se as doenças mentais.

A tabela 9 mostra quais eram as providências tomadas pelos moradores da favela em caso de doença. 


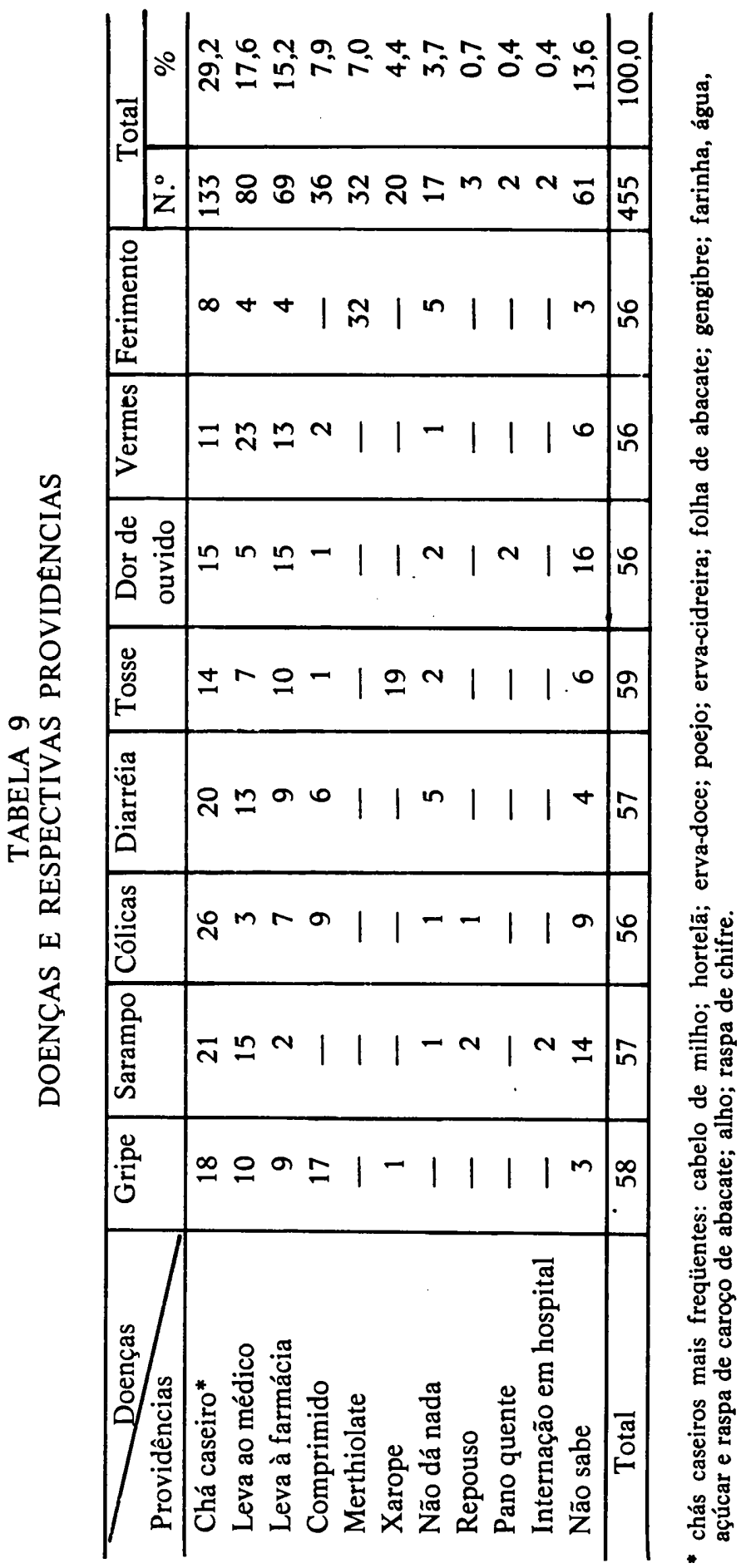


6. Comunicação, recreação e liderança informações:

Com relação à esses aspectos obtiveram-se as seguintes

- das 55 famílias existentes, $41(74,5 \%)$ liam jornais e revistas; os jornais mais lidos eram os do município de São Paulo e as revistas mais lidas, as fotonovelas;

- do total de famílias entrevistadas, apenas $30(56,3 \%)$ indicaram ter alguma atividade recreativa; verificou-se em ordem decrescente que: ou estava relacionada às atividades religiosas ou à convivência com vizinhos e parentes ou ao uso de rádio e televisão, ou à prática de jogos de futebol e freqüência a eles;

- todas as famílias ficavam sabendo dos fatos que ocorriam na favela, por meio de conversas com vizinhos, parentes e amigos;

- não foi identificada nenhuma pessoa influente na favela, quando foi preciso ajuda para resolver problemas tais como: falta de dinheiro, socorro a pessoas doentes, obtenção de emprego, alimentos ou melhoria das condições da habitação, essa ajuda foi pedida a:

- vizinhos $(44,8 \%)$;

- amigos $(25,0 \%)$;

- parentes $(23,7 \%)$;

- padre e prefeito $(18,4 \%)$;

- uma pequẹna porcentagem $(29,0 \%)$ de famílias informou que nunca pediu ou pediria ajuda a ninguém e os motivos alegados foram: "tinham vergonha", "não precisavam", "não adiantava", "ninguém tinha coņdições de ajudar", "não houve necessidade".

7. Motivos para morar na favela, problemas existentes e perspectivas futuras

As famílias que moravam na favela deram os seguintes motivos para explicar porque vieram morar no local: 
- $37(69,0 \%)$ porque não podiam pagar aluguel;

- $15(27,0 \%)$ porque não tinham para onde ir;

- $3(5,5 \%)$ porque era mais cômodo pois ficava perto do emprego.

O tempo de residência das famílias na favela encontra-se na tabela 10.

TABELA 10

TEMPO DE RESIDENCIA DAS FAMILIAS NA FAVELA

\begin{tabular}{c|c|c}
\hline Tempo de residência & N. $^{\circ}$ famílias & $\%$ \\
\hline $0-1$ ano & 2 & 3,6 \\
$1-3$ anos & 20 & 36,3 \\
$3-5$ anos & 15 & 27,2 \\
$5-10$ anos & 13 & 23,6 \\
+ de 10 anos & 5 & 9,0 \\
\hline Total & 55 & 100,0 \\
\hline
\end{tabular}

A respeito da vontade ou não de mudar de local de residência, as informações foram as seguintes:

- 10 famílias $(18,2 \%)$ informaram não querer mudar;

- 45 famílias $(81,8 \%)$ gostariam de mudar.

As razões apontadas pelas famílias que não queriam mudar, foram as seguintes: 4 gostavam do local, 3 gostavam dos vizinhos, 2 não podiam pagar aluguel, 1 tinha conforto.

As famílias que gostariam de mudar da favela deram as seguintes razōes: 17 porque faltava conforto - "barracos frios, chovia dentro, faltava água, havia muita sujeira" -; 16 "porque corriam 0 risco de perder a casa pois o terreno era da prefeitura" $e$, por outro lado, "não tinham gosto em fazer melhoramentos numa casa que não era sua"; 12 porque "eram chamados de maloqueiros, havia prostitutas no local e sentiam-se envergonhados". 
Dos que gostariam de mudar da favela, $14(31,1 \%)$ optaram por morar no próprio bairro, $16(35,5 \%)$ fora do bairro e 15 $(33,4 \%)$, indiferentemente, fora ou no próprio bairro.

Os motivos apontados pelas famílias que gostariam de mudar para outro bairro foram os seguintes: desejavam morar perto de conhecidos e parentes; estavam pagando prestação de terreno em outro local; queriam um local com mais conforto ou onde não houvesse brigas e tivesse melhor reputação.

Os motivos apontados pelas famílias que queriam morar no próprio bairro foram: gostavam do bairro e já estavam acostumados; havia escola perto para os filhos; gostavam dos vizinhos; o local era perto do trabalho.

Os que optaram por morar, indiferentemente, fora ou no próprio bairro disseram que o local da nova moradia poderia ser qualquer um desde que a casa fosse própria ou um em que houvesse mais conforto.

Apenas 30 famílias $(54,5 \%)$ indicaram ter problemas no momento. Os problemas existentes na favela, segundo os informantes, estão em ordem decrescente, na tabela 11.

TABELA 11

PROBLEMAS EXISTENTES NA FAVELA

\begin{tabular}{l|r|r}
\hline \multicolumn{1}{c|}{ Problemas } & $\mathrm{N}^{\circ}$ & $\%$ \\
\hline Más condições de habitação* & 18 & 42,0 \\
Brigas & 8 & 18,0 \\
Dificuldades financeiras e falta de emprego & 6 & 14,0 \\
Morar em terreno não próprio e desfavelamento & 6 & 14,0 \\
Vergonha da condição de favelado & 5 & 11,6 \\
Doenças & 1 & 2,3 \\
Prostituição & 1 & 2,3 \\
\hline \multicolumn{1}{c|}{ Total } & 43 & 100,0 \\
\hline
\end{tabular}

* falta de luz elétrica, barraco desconfortável, córrego mau cheiroso, água de poço contaminada, quintal coletivo.

Mais da metade $(58 \%)$ dos moradores que informou ter tido problemas alegava que ninguém os tinha ajudado a resolvê-los. Outros apontaram algumas instituições ou pessoas que os tinham ajudado 
algumas vezes, como: o dono do armazém do bairro $(6,3 \%)$, a polícia $(2,1 \%)$, a igreja $(8,4 \%)$, os amigos ou vizinhos $(12,6 \%)$. Outros $(8,4 \%)$ não se lembravam de ter recebido alguma ajuda.

De um modo geral, uma grande parte $(54,6 \%)$ não imaginava quem poderia ajudá-los. Alguns $(20,9 \%)$ apontavam a prefeitura como a instituição capacitada para resolver todos os seus problemas; outros, seus parentes e vizinhos $(11,5 \%)$; outros, ainda, a igreja $(7,2 \%)$ ou a polícia $(7,2 \%)$. Um grupo $(9,4 \%)$ alegava que ninguém estava capacitado a resolver seus problemas.

Com relação às propostas para a resolução dos problemas da favela, uma boa parte $(30,9 \%)$ dos entrevistados disse que não sabia como resolvê-los. A maioria deu as seguintes sugestões:

- iniciar o desfavelamento, mas com um prazo para a mudança dos moradores $(19,3 \%)$;

- melhorar as condições da habitação - pedir água e esgoto $(14,9 \%)$;

— pedir ajuda à prefeitura ou à escola $(12,4 \%)$;

- trocar de vizinhos ou dar parte à polícia a respeito dos mesmos $(10,0 \%)$;

- pedir empréstimo de dinheiro a alguém (5\%);

- arranjar aluguel mais barato $(2,5 \%)$;

- comprar terreno $(2,5 \%)$;

— pedir "cesta de natal" $(2,5 \%)$.

A respeito dos problemas familiares, 30 entrevistados $(54,5 \%)$ disseram existir nas suas famílias, em ordem decrescente, os seguintes:

- situação econômica precária; 
- receio de serem despejados sem condições de se mudar;

- doenças na família.

Quanto às soluções para esses problemas, metade não sabia como poderiam ser resolvidos e a outra metade deu as seguintes sugestões em ordem decrescente:

- trabalhar e juntar dinheiro para mudar e melhorar de vida;

- conseguir auxílio da prefeitura, igreja ou polícia local;

- conseguir casa própria;

- tratar da saúde.

Duas mulheres entrevistadas disseram: os problemas seriam resolvidos "só morrendo" e outra "só se separando do marido".

Com relação às perspectivas futuras, as informações foram as seguintes: 45 famílias $(81,45 \%)$ acreditavam que suas vidas poderiam vir a mudar. Os meios apontados para conseguir essa mudança, encontram-se na tabela 12.

TABELA 12

MEIOS PARA CONSEGUIR MUDAR DE VIDA

\begin{tabular}{l|r|r}
\hline \multicolumn{1}{c|}{ Meios } & $\mathrm{N}^{\circ}$ & $\%$ \\
\hline Filhos em idade de trabalhar & 26 & 47,4 \\
Mudança de domicílio & 10 & 17,9 \\
Mudança de emprego do chefe & 7 & 12,5 \\
Fé religiosa & 4 & 7,1 \\
Todos da família trabalhando & 4 & 7,1 \\
Fazendo economia & 2 & 3,5 \\
Alguém auxiliando a família & 1 & 1,7 \\
Loteria & 1 & 1,7 \\
Não sabe como & 1 & 1,7 \\
\hline \multicolumn{1}{c|}{ Total } & 56 & 100,0 \\
\hline
\end{tabular}

Todas as pessoas entrevistadas informaram que não desejavam que a sua família aumentasse e deram as seguintes respostas sobre 
planejamento familiar: $15(27 \%)$ casais evitam ter filhos e $38(68,4 \%)$ não evitam. Como nem sempre o entrevistado era o chefe da família ou a esposa, $2(4,6 \%)$ não souberam dar mais informações a respeito.

Grande parte dos chefes de família ou esposas entrevistadas, que tinham filhos disseram que gostariam que os filhos tivessem um futuro diferente do seu, inclusive com uma profissão diferente da sua. Alguns $(24 \%)$ eram indiferentes a esse respeito e outros $(5,5 \%)$ não haviam pensado em nada. Aqueles que se manifestaram em relação ao fato de que os filhos tivessem uma profissão diferente da sua apontaram como as melhores, ou como aquelas que mais lhe agradavam as seguintes ocupações:

- técnicas especializadas - desenhista, professora, mecânico, motorista, carpinteiro, operário de fábrica, bancário, escriturário e costureira - $(65,4 \%)$;

- liberais - medicina, engenharia, advocacia $(28,5 \%)$;

- outras - proprietário, pastor ou qualquer profissão que tenha estudo - $(6,1 \%)$.

As razões por que as famílias gostariam de que os filhos tivessem as profissões anteriormente citadas foram:

- os filhos teriam melhores condições econômicas ...... $(70,4 \%)$;

- a profissão era bonita $(14,8 \%)$;

- os filhos tinham vocação para tal $(7,4 \%)$;

- elas permitiriam que os filhos continuassem próximos às famílias podendo cuidar delas $(7,4 \%)$.

8. Como a comunidade via a favela

O presidente da associação de amigos do bairro local deu as seguintes informações a respeito da favela: a favela existia há mais 
ou menos quinze anos e as condições sócio-econômicas dos moradores sempre tinha sido muito precárias; os salários sempre muito baixo, existindo alguns moradores do sexo masculino que não trabalhavam, vivendo do salário das mulheres que eram empregadas domésticas. Acrescentou ainda que algumas associações religiosas filiadas à igreja da paróquia local ajudavam as famílias mais necessitadas que, na sua opinião, "servia para viciá-los a não trabalharem".

Alguns moradores da favela freqüentavam o MOBRAL e a Sociedade Amigos do Bairro fornecia material escolar aos alunos.

O bairro onde estava localizada a favela, de acordo com as informações do presidente da associação de amigos do bairro local, sofria uma média de três assaltos por semana e os moradores do bairro responsabilizavam os favelados por esses assaltos. Alegou que eles não viam "com bons olhos" a favela, consideravam que ela "tornava o ambiente desagradável" e queriam o desfavelamento para poder construir uma associação esportiva ou uma creche no terreno onde a favela se localizava e, além disso, achavam que a saída dos favelados viria valorizar os terrenos de suas casas. Informou, ainda, que a prefeitura local havia feito uma intimação para os favelados desocuparem a área mas alguns ficaram revoltados porque não haviam sido avisados. Outros chegaram a ir embora, voltando novamente a morar na favela quando perceberam que ela continuava no mesmo local. Outros, ainda, diziam que se fossem mandados embora construiriam seus barracos em outro local, iniciando outra favela.

Como solução para o problema da favela, o presidente da associação de amigos do bairro sugeriu que a prefeitura fizesse um levantamento das suas condições como das dos seus moradores e construisse casas populares, vendendo-as a preços bem acessíveis.

\section{COMENTARIOS}

A favela se caracterizava por possuir uma população jovem, cuja contribuição para a atividade econômica deveria ser bem pequena, pois quase a metade dos moradores tinha menos de 12 anos e apenas uma minoria possuia mais de 50 anos; além disso, havia um número maior de homens em relação ao número de mulheres. 
Os adultos afirmavam estar "legalmente casados" mas apenas metade dizia possuir certidão de casamento civil o que leva a supor que talvez tenha considerado o casamento religioso como legal, ou ainda, por motivos pessoais, preferiram afirmar que estavam "legalmente casados".

A religião mais apontada foi a católica mas se acredita que o número de indivíduos que realmente professavam tal religião estava acima da realidade, igualmente como acontece em levantamentos realizados no resto do país.

A escolaridade era muito baixa: existia um bom número de analfabetos e os que tinham freqüentado a escola, tinham apenas o primário. Por outro lado, mais da metade destes nem o havia concluido.

As condições econômicas eram bem precárias, não só pelo tipo de ocupação que tinham, mas pelo número reduzido de adultos que trabalhavam. Podem-se imaginar ainda as dificuldades que tinham os favelados para conseguir outro tipo de ocupação, não só devido à escolaridade, mas também porque uma boa parte dos adultos nem certidão de nascimento possuia.

A maioria desconhecia as causas da morte dos seus familiares mas, alguns informaram a existência de causas ligadas ao ciclo grávido-puerperal.

Como as condições de habitação eram precárias, devia ser grande a incidência de doenças respiratórias e gastrointestinais e, talvez, a população não tenha dado informações a respeito por não ser um problema sentido por ela.

Quando ficavam doentes, procuravam em primeiro lugar o Pronto Socorro Municipal, o que leva a supor que a procura de assistência médica era feita em casos de extrema necessidade. Vale a pena ressaltar, por outro lado, que, embora com menor freqüência, o farmacêutico e o benzedor também eram procurados em caso de doença.

Apenas metade das famílias informou ter direito à previdência social e a maioria dos adultos e crianças não tinham assistência 
dentária de nenhuma espécie. Uma parte das crianças tinha recebido algumas vacinas no posto de saúde da prefeitura local.

A alimentação básica era constituída de arroz, feijão, café e pão e a fonte de abastecimento mais utilizada era o armazém, talvez por fornecer mantimentos que poderiam ser pagos no fim do mês por ocasião do recebimento dos ordenados. Por outro lado, os favelados não plantavam verduras no pouco terreno que possuiam, o que talvez pudesse contribuir para a melhoria da alimentação.

Quanto à vida social, incluindo recreação, vimos que a maioria possuia rádio e algumas famílias, embora tivessem condições econômicas precárias, tinham até televisão. Muitas liam jornais e revistas, principalmente fotonovelas. A maioria não tinha vida associativa e os poucos que a tinham restringiam-se a associações religiosas. Quanto às notícias, a maioria ficava sabendo do que acontecia por meio de vizinhos. Não foram identificados líderes informais na favela.

Quanto às perspectivas futuras, vimos que a maioria das famílias queria melhorar de vida e isto estava condicionado ao fato dos filhos terem profissões melhores do que a dos pais.

Todos os casais da favela não queriam ter mais filhos, mas somente menos da metade usava meios para evitá-los.

A maioria das famílias informou querer mudar de local de habitação e as razões estavam ligadas à falta de conforto, instabilidade na fixação de residência e promiscuidade.

Foram apontados vários problemas existentes na favela, não só pelos próprios favelados como por pessoas moradoras fora dela. Eram problemas relacionados às condições precárias da habitação e problemas sociais, tais como desemprego e mal relacionamento humano. $\mathrm{Pa}$ recia, por outro lado, que o bairro rejeitava a favela e queria que a prefeitura local fizesse o desfavelamento.

Quanto a resolução dos seus problemas, os favelados, em sua maioria, não tinham idéia a quem deveriam recorrer ou não tinham idéia de como poderiam resolvê-los. Foi citado, entretanto, embora por 
pequeno número de pessoas, algumas instituições tais como a igreja e a polícia como capazes de resolver alguns deles.

\section{CONCLUSOES}

A favela, como era de se esperar, era constituída de um aglomerado de famílias com graves problemas sócio-econômicos que interferiam diretamente nas suas condições de saúde, condições estas, impossíveis de serem melhoradas se não fossem solucionadas as causas básicas.

De um modo geral, a população sentia alguns problemas relacionados a esses fatos mas não tinha condições nem iniciativa para, sozinha, interromper esse ciclo vicioso.

Para o profissional de saúde é importante conhecer os aspectos sócio-econômicos de uma população, pois um programa de saúde, quando não acompanhado de outros que visem ao desenvolvimento da comunidade como um todo, pouco adiantará.

NOGUEIRA, M. J. C. et al - Characteristics of a slum area of Greater São Paulo. Rev. Esc. Enf. USP, 10(2): 230-248, 1976.

The authors describe results of a survey on social-economical conditions of a slum area of Greater São Paulo, wich is an industrial region of south-eastern Brazil. 